\title{
Management of Arsenicosis by Intake of Proper Foods and Vitamin C Supplementation
}

\author{
A. K. B. Zaman ${ }^{1}$, Md Fazlul Haque ${ }^{2, *}$ \\ ${ }^{1}$ Department of Dermatology, Barind Medical Collage, Rajshahi, Bangladesh \\ ${ }^{2}$ Departemnt of Zoology, Rajshahi University, Rajshahi, Bangladesh
}

Email address:

dr.bzaman@gmail.com (A. K. B. Zaman), jeweljanna@yahoo.com (M. F. Haque)

\section{To cite this article:}

A. K. B. Zaman, Md Fazlul Haque. Management of Arsenicosis by Intake of Proper Foods and Vitamin C Supplementation. International Journal of Nutrition and Food Sciences. Vol. 4, No. 6, 2015, pp. 676-680. doi: 10.11648/j.ijnfs.20150406.22

\begin{abstract}
Arsenicosis, a disease caused by toxicity of arsenic, has been reported as a severe global health threat for the millions of peoples who are bound to use arsenic contaminated ground water as the main source of drinking water. Arsenicosis can be managed by using synthetic remedies. But, most of these synthetic remedies have side effect and/or are costly for the people of poor countries where arsenicosis is more prevalent. Hence, research on an alternative strategy for management of arsenicosis is important for public health. In this study, as a strategy to manage arsenicosis, a diet regime containing proper foods and vitamin $\mathrm{C}$ supplementation was suggested to follow for six months by arsenicosis patients who were selected from three study areas located in northwestern districts (Nawabganj and Rajshahi) of Bangladesh. It was found that the suggested diet regime can cause significant reduction of urinary arsenic excretion, enhancement of blood hemoglobin level, and improvement of keratosis condition in investigated arsenicosis patients after following the diet regime for six months, indicating a positive role of diet regime on betterment of health condition of arsenicosis patients.
\end{abstract}

Keywords: Diet Regime, Proper Foods, Vitamin C, Arsenic, Arsenicosis

\section{Introduction}

Arsenic contamination in ground water has been reported as a severe health threat for the population who are using contaminated water for drinking and/or for cooking their meal $[1,2]$. According to the World Health Organization, the maximum permissible limit of arsenic in drinking water is 10 $\mu \mathrm{g} / \mathrm{L}(0.01 \mathrm{ppm})$ [3]. In Bangladesh, ground water with contaminated arsenic above the permissible limit has been found in 59 districts out of 64 districts [4]. Around 24 million people are exposed potentially to arsenic contaminated water collected from hand-pumped tube-wells in Bangladesh, and 8500 people of them are seriously suffering from toxic effect of arsenic, known as arsenicosis [4]. Similarly, a large population from different states (West Bengal, Bihar, Uttar Pradesh, Modhya Pradesh etc.) in India is using arsenic contaminated water yielded from tube-wells, even some of them with very high concentration of arsenic (up to 3400 $\mu \mathrm{g} / \mathrm{L}$ ) [5-7]. Recently, it has been reported that millions of people in the USA and in many European countries are exposed to arsenic contaminated drinking water [5-7]. Hence, arsenic contamination in drinking water is now considering as global health threat.

To manage arsenicosis many types of synthetic medicines such as 2,3-dimercaprol and meso2,3-dimercaptosuccinic acid which are metal-chelating agents have been used in many cases. However, most of the synthetic remedies have some forms of disadvantages such as toxic side effects on patients [8]. Hence, searching for antidotes without sideeffect to manage arsenicosis effectively is a demand of time. As many types of foods, especially vegetable contains several classes of antioxidant compounds, it has been suggested that consumption of these types of foods lead to reduction of toxic compounds in humane body resulting health benefit [9-11]. Moreover, several studies have revealed that dietary supplementation with selective foods and vitamin is positively correlated with the decline of toxic effect of various environmental agents such as heavy metals [12]. Hence, developing a diet-chart using appropriate foods and vitamin supplementation may be an effective strategy to manage arsenicosis without any side effect. In this study, investigated patients with arsenicosis were motivated to follow a diet regime containing proper foods and vitamin $\mathrm{C}$ supplementation for six months with an aim that their condition would be better after that time. Interestingly, it was 
found that health condition of investigated patients was improved remarkably as shown by significance difference in several parameters which were investigated to compare severity of arsenicosis before following diet regime with that after following diet regime. Thus, the finding of this study is indicating that a diet regime with proper foods and vitamin supplementation may be an effective strategy to manage arsenicosis.

\section{Materials and Methods}

\subsection{Selection of Study Areas and Samples}

In this study, three villages from two northwestern districts (Nawabganj and Rajshahi) of Bangladesh were selected as study areas (Table 1) on the basis of specific subjects identified those having skin lesions caused by continuous arsenic exposure from drinking water. To avoid ambiguity, at first, patients with arsenicosis were identified upon their arrival at hospital for seeking outdoor service. After that a link was established to trace their community with an intention to find out more cases of arsenicosis. Total 200 people (70 from SA-1, 70 from SA-2 and 60 from SA-3) were interviewed from three study areas to select 36 (12 from each area) arsenicosis patients who were voluntarily interested to take part in this study for further investigation and experimental management of their arsenicosis.

Table 1. Basic information on the three study areas.

\begin{tabular}{lllll}
\hline Area & Village & $\begin{array}{l}\text { Police } \\
\text { station }\end{array}$ & District & Population \\
\hline $\begin{array}{l}\text { Study Area-1 } \\
\text { (SA-1) }\end{array}$ & Namosankarbati & Nawabgang & Nawabgang & 4000 \\
$\begin{array}{l}\text { Study Area-2 } \\
\text { (SA-2) }\end{array}$ & Ranihati & Nawabgang & Nawabgang & 6000 \\
$\begin{array}{l}\text { Study Area-3 } \\
\text { (SA-3) }\end{array}$ & Saidara & Bagmara & Rajshahi & 1700 \\
\hline
\end{tabular}

\subsection{Analysis of Water Samples for Arsenic}

Total 60 water samples (20 from each study area) were collected from 60 different tube-wells which were usually used as sources of drinking water by selected patients. Then, water samples which were contained in clean plastic bottles were preserved in refrigerator at $4^{\circ} \mathrm{C}$. The collected water samples were analyzed for arsenic concentration by modified spectrometric technique as described by Tahir and their colleague, 2012 [13].

\subsection{Implementation of Diet Regime}

The selected patients were invited to attend a day long discussion on a diet regime (Table 2) and its importance on reduction of toxicity caused by heavy metals. By the open discussion they were motivated to follow the diet regime for six months. Then, discussion was conducted individually to each patient for helping him/her to select appropriate foods depending on their food habits and economic condition to follow the diet regime.
Table 2. Dietary Regime given to the patients for at least six months to follow.

\begin{tabular}{ll}
\hline Dietary factor & $\begin{array}{l}\text { Consultation and Recommendations for } \\
\text { Daily Dietary Intake (considering about 3500 } \\
\text { calories required in a day) }\end{array}$ \\
\hline Total Fat & $\begin{array}{l}15-30 \% \text { of required calories (correspond to } 70- \\
100 \mathrm{~g} \text { edible oil) }\end{array}$ \\
& $55-75 \%$ of required calories (correspond to \\
Total carbohydrate & $450-500 \mathrm{~g}$ of complex sugar eg. starch) \\
& $10-15 \%$ of required calories (correspond to \\
& $125-150 \mathrm{~g}$ net protein) \\
Protein & $<3 \mathrm{~g}$ per day \\
Sodium chloride (salt) & $\geq 200 \mathrm{~g}$ per day \\
Vegetables & $\geq 50 \mathrm{~g}$ per day \\
Pulse, nuts and seeds & $1000 \mathrm{mg}$ (as part of the 200 g of total fruits) \\
Vitamin C & \\
Safe Drinking water & \\
(from tube wells & $2500 \mathrm{~mL}$ to $4000 \mathrm{~mL}$ per day (depending on \\
sources those brought & nature of activity in that particular day) \\
under investigation) & \\
Total dietary fiber & From fiber-rich food (about 50 g) \\
\hline
\end{tabular}

\subsection{Analysis of Urine for Arsenic}

Before and after diet regime following, the morning-hour urine from selected patients were collected in clean and labeled plastic bottles which were then transported to the laboratory for arsenic analysis. Then, collected urine was analyzed for measuring arsenic concentration by Atomic absorption spectrophotometry (AAS) method for biomarker samples as described by Dang and their colleague, 1999 [14].

\subsection{Analysis of Hemoglobin in Blood}

Before and after diet regime following, blood samples were collected from selected patients in the labeled tubes. Then, the collected blood samples were transferred to a private diagnostic center located at Rajshahi city, Bangladesh for analysis of hemoglobin in supplied samples.

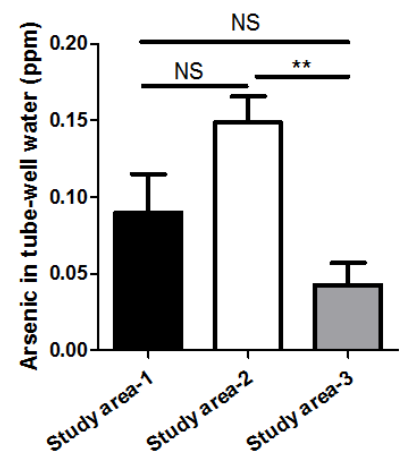

Figure 1. Arsenic concentration in water from 20 tube wells of each study area. The detection limit (DL) of the method used was $20 \mathrm{ppb}( \pm 10 \mathrm{ppb})$, that corresponds $0.02 \mathrm{ppm}( \pm 0.01 \mathrm{ppm})$, therefore arsenic concentrations those were found less than $20 \mathrm{ppb}$ are put here as $0.01 \mathrm{ppm} .{ }^{\mathrm{NS}} \mathrm{P} \geq 0.05$, $* * P<0.01$.

\subsection{Analysis of Degree of Keratosis}

Before and after diet regime following, patients were investigated to analyze the grade of keratosis in their body. Depending on degree of keratosis and their distribution on body parts, patients were categorized into three types i.e. (a) 
Spotted keratosis on palms/soles (least severe form), (b) Diffuse keratosis on palms/soles (moderate severe form), and (c) Dorsal keratosis (most severe form).

\subsection{Statistical Analysis}

Data were pooled for presentation as mean \pm SEM. All data were analyzed with Prism software (GraphPad, La Jolla, CA, USA) using two-tailed unpaired Student's t-tests. Pvalues $<0.05$ were considered significant.

\section{Results}

In 3 studied areas, total 200 people were interviewed to find out the sources of their drinking water. It was found that more than $98 \%$ of people were using tube-wells as the source

A
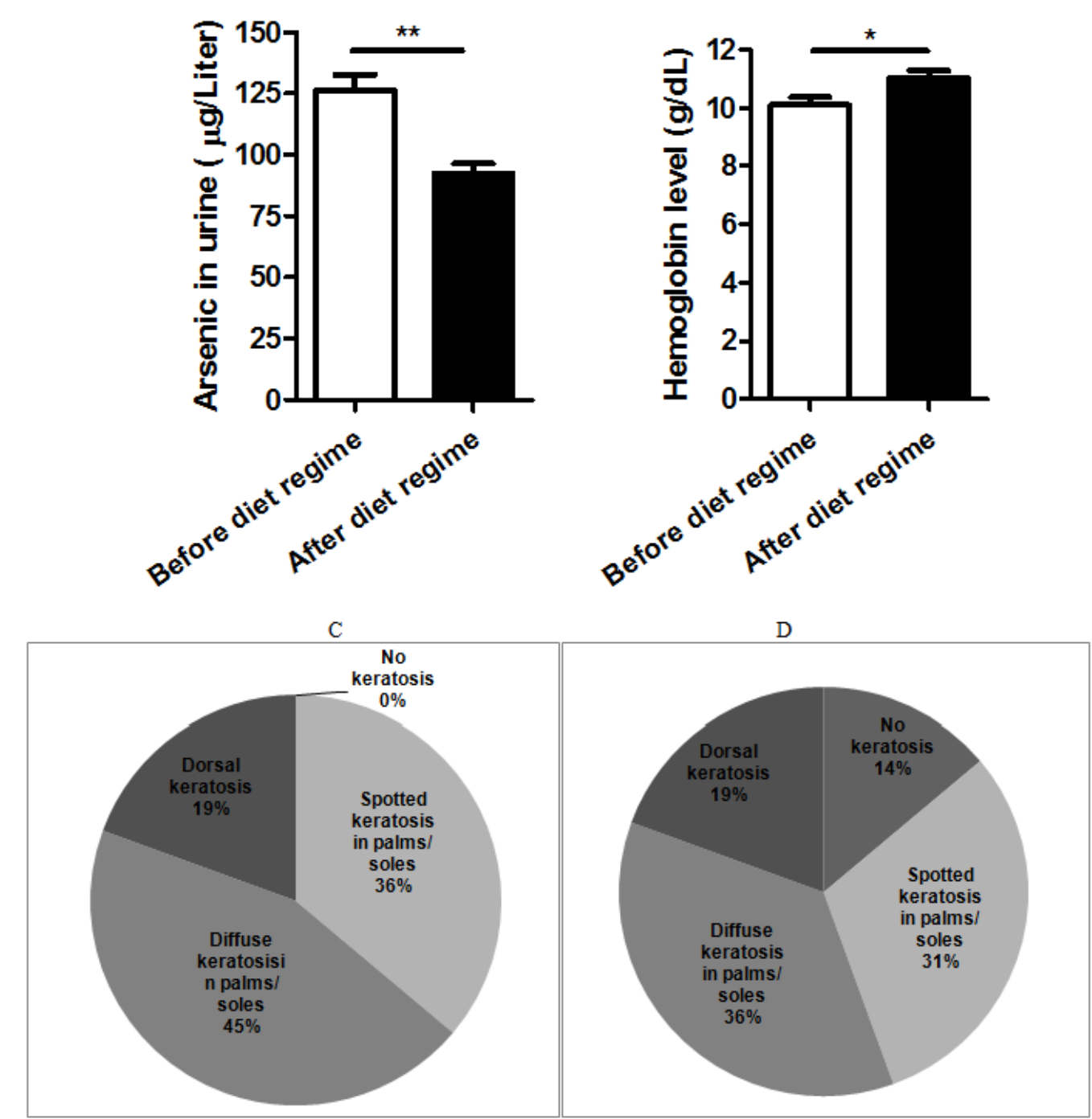

Figure 2. Betterment of health condition of the patients with arsenicosis resulted from suggested diet regime. A diet regime with proper foods and vitamin $C$ supplementation was prepared. Then, 36 patients from 3 study areas were selected and motivated to follow the suggested diet chart for 6 month. Just before starting suggested diet regime, different markers of arsenicosis in investigated patients were measured and recorded as control to compare with same parameters after 6 months of diet regime following. (A) is a comparison of arsenic level in urine between before and after diet regime following. (B) is a comparison of hemoglobin level in red-blood cells between before and after diet regime following. (C) and (D) are percent of investigated patients with different degree of keratosis before and after diet regime respectively. $* P<0.05$, $* * P<0.01$.

of drinking water (data not shown). Then, total 60 water samples (20 samples from each area) which were collected randomly from 3 study areas were analyzed for quantifying the arsenic concentration in those samples. As shown in Figure 1, the higher concentration of arsenic in tube-well water was found in study area- 2 followed by study area- 1 and 3. However, these differences of arsenic concentration in tube-well water was statistically significant only between study area-2 and study area-3 (Figure 1). Nevertheless, arsenic concentrations in tube-well water in all three studied areas were above the permissible limit $(0.01 \mathrm{ppm})$ set by World health organization [3] indicating that people of three studied areas were might be affected by toxicity of arsenic by drinking tube-well water.

\section{B}


It has been revealed by several studies that intake of proper foods which are rich in antioxidant and vitamins can cause the reduction of toxic effect of heavy metal in animal body [9-11]. Hence, it was assumed that arsenic toxicity might be lessened by consumption of proper foods and vitamin $\mathrm{C}$ resulting in health improvement in patients suffering from arsenicosis. To test this assumption, selected patients with arsenicosis were motivated to follow the suggested diet regime for 6 months. It was found that arsenic level in urine, a marker of arsenicosis, was reduced significantly by following suggested diet regime for six months (Figure. 2A). Similarly, hemoglobin level in blood, another marker of arsenicosis, was increased significantly by six-month use of suggested diet regime (Figure. 2B). Moreover, degree of keratosis which is usually used for grading the severity of arsenicosis was lessened by using suggested diet regime (Figure. $2 \mathrm{C}$ and D). However, sign of keratosis was disappeared in $14 \%$ of arsenicosis patients after six month diet regime (Figure. 2 D) while no change in percentage was found for patients with the most severe form of keratosis (dorsal keratosis) (Figure. $2 \mathrm{C}$ and $\mathrm{D}$ ) indicating that only diet regime is not enough to manage the severe form of arsenicosis. Altogether, it can be concluded that following a diet regime containing proper foods and vitamin $\mathrm{C}$ supplementation for six months is an effective strategy for reducing arsenic toxicity in patients suffering from arsenicosis.

\section{Discussion}

As shown by results of the studied markers of arsenicosis, remarkable health improvement was observed in the investigated patients by following suggested diet regime for six months. However, using proper diet with vitamin supplementation to reduce toxicity of heavy metal in animal body is a well-studied mechanism. For example, a study revealed that oxidative stress induced by arsenite can be remarkably prevented by combined intake of $\alpha$-lipoic acid and vitamin $\mathrm{C}$ during arsenite exposure in animals [7]. Likewise, it has been shown by an in-vitro study that HL60 and $\mathrm{U} 266$ cells have been protected from arsenic toxicity by vitamin C [15]

In this study, it was found that arsenic level in urine, a marker of arsenicosis[16], was significantly reduced by following diet regime for six months. It has been revealed by a study that vitamin $\mathrm{B}$, vitamin $\mathrm{C}$ and soy isoflavones can reduce urinary inorganic Arsenic significantly [17]. Conversely, urinary arsenic excretion can be increased (10-15\%) by greater intake of protein, methionine, and cysteine[18]. Actually, the newer and improved diet regime might be involved in different pathway of metabolism resulting in different distribution pattern for excreted arsenic. Hence, further investigation is required for explaining the role of suggested diet regime on reduction of arsenic level in urine.

It was found in this study that the amount of hemoglobin in blood was increased significantly by suggested diet regime. Importantly, it has been reported by a study that level of hemoglobin in blood has been correlated with severity of arsenicosis[19]; hence it can be considered as a biomarker of severity of arsenicosis. In another study, arsenic has been shown as a causative agent of reversible megaloblastic anemia [20]. Similarly, an association between low level of hemoglobin and high arsenic exposure was observed in a study in Bangladesh[21]. Interestingly, it has been shown by a study that arsenic induced anemia in rat can be recovered by iron supplemented food [22].

Clinical keratosis is divided into following grades, (1) Spotted keratosis in palms/soles, (2) Diffuse keratosis in palms/soles, and (3) Dorsal keratosis [23]. In this study, it was found that health condition of studied patents was improved remarkably in respect of severity of keratosis after following diet regime for six months. Likewise, it has been reported by another study that supplementation of vitamins $\mathrm{A}, \mathrm{C}$, and $\mathrm{E}$ and related foods can reduce the number, distribution and size of keratosis caused by arsenic toxicity [24].

\section{Conclusion}

In this study, it was found that a diet regime containing proper foods and vitamin $\mathrm{C}$ supplementation can cause significant reduction of urinary arsenic excretion, enhancement of blood hemoglobin level, and improvement of keratosis condition in investigated arsenicosis patients after following the diet regime for six months. As all of these changes were indicators of betterment of health condition of arsenicosis patients, it can be concluded that the diet regime with proper foods and vitamin $\mathrm{C}$ supplementation can play an effective role in management of arsenicosis in those area where people were using arsenic contaminated tube-well water as the main source of drinking water.

\section{References}

[1] Human Exposure; Arsenic in Drinking Water., in Some drinking-water Disinfectants and contaminants, including Arsenic. IARC Monographs on the Evaluation of Carcinogenic risks to Humans,. 2004, World Health Organization: Lyon France. p. 60-188.

[2] Chowdhury, U.K., et al., Groundwater arsenic contamination in Bangladesh and West Bengal, India. Environ Health Perspect, 2000. 108(5): p. 393-7.

[3] Kumar, M. and A. Puri, A review of permissible limits of drinking water. Indian journal of occupational and environmental medicine, 2012. 16(1): p. 40.

[4] Arsenic Calamity of Bangladesh. On-line Arsenic Page 2000; Available from: www.dainichi-consul.co.jp/english/arsen.html.

[5] Guha Mazumder, D.N., et al., Randomized placebo-controlled trial of 2,3-dimercaptosuccinic acid in therapy of chronic arsenicosis due to drinking arsenic-contaminated subsoil water. Clinical Toxicology, 1998. 36(7): p. 683-690. 
[6] Pandey, P., et al., Arsenic contamination in the Kanker district of central-east India: geology and health effects. Environmental geochemistry and health, 2006. 28(5): p. 409420.

[7] Kaur, H., et al., Co-administration of $\alpha$-lipoic acid and vitamin $\mathrm{C}$ protects liver and brain oxidative stress in mice exposed to arsenic contaminated water. Water Quality, Exposure and Health, 2009. 1(3-4): p. 135-144.

[8] Mehta, A. and S. Flora, Possible role of metal redistribution, hepatotoxicity and oxidative stress in chelating agents induced hepatic and renal metallothionein in rats. Food and chemical toxicology, 2001. 39(10): p. 1029-1038.

[9] Flora, S.J., A. Mehta, and R. Gupta, Prevention of arsenicinduced hepatic apoptosis by concomitant administration of garlic extracts in mice. Chemico-biological interactions, 2009. 177(3): p. 227-233.

[10] Rabbani, G.H., et al., Antioxidants in detoxification of arsenic-induced oxidative injury in rabbits: preliminary results. Journal of Environmental Science and Health, Part A, 2003. 38(1): p. 273-287.

[11] Zablotska, L.B., et al., Protective effects of B vitamins and antioxidants on the risk of arsenic-related skin lesions in Bangladesh. Environ Health Perspect, 2008. 116(8): p. 10561062 .

[12] Flora, S., Lead in the environment: prevention and treatment. J. Environ. Biol, 2002. 23: p. 29-44.

[13] Tahir, M., H. Rasheed, and A. Malana, Method development for arsenic analysis by modification in spectrophotometric technique. Drinking Water Engineering and Science, 2012. 5(1): p. 1-8.

[14] Dang, T.M., Q.T. Tran, and K.V. Vu, Determination of arsenic in urine by atomic absorption spectrophotometry for biological monitoring of occupational exposure to arsenic. Toxicol Lett, 1999. 108(2-3): p. 179-83.
[15] Karasavvas, N., et al., Vitamin C protects HL60 and U266 cells from arsenic toxicity. Blood, 2005. 105(10): p. 40044012 .

[16] Mazumder, D.G., Diagnosis and treatment of chronic arsenic poisoning. United Nations Synthesis Report on Arsenic in Drinking Water, 2000.

[17] Ilmiawati, C., et al., Urinary arsenic excretion profiles and associated dietary factors in Japanese women from a coastal area in Chiba Prefecture.

[18] Heck, J.E., et al., Dietary intake of methionine, cysteine, and protein and urinary arsenic excretion in Bangladesh. Environ Health Perspect, 2009. 117(1): p. 99-104.

[19] Sikder, M., et al., Association between anemia and grading of arsenicosis. Journal of Pakistan Association of Dermatologists, 2008. 18: p. 202-206.

[20] Westhoff, D., R. Samaha, and A.J. Barnes, Arsenic intoxication as a cause of megaloblastic anemia. Blood, 1975. 45(2): p. 241-246.

[21] Heck, J.E., et al., Arsenic exposure and anemia in Bangladesh: a population-based study. Journal of Occupational and Environmental Medicine, 2008. 50(1): p. 80-87.

[22] Myers, V.C., H.H. Beard, and B.O. Barnes, Studies in the nutritional anemia of the rat iv. the production of hemoglobinemia and polycythemia in normal animals by means of inorganic elements. Journal of Biological Chemistry, 1931. 94(1): p. 117-122.

[23] Saha, K.C., Diagnosis of arsenicosis. Journal of Environmental Science and Health, Part A, 2003. 38(1): p. 255-272.

[24] Keller, K.L. and N.A. Fenske, Uses of vitamins A, C, and E and related compounds in dermatology: a review. Journal of the American Academy of Dermatology, 1998. 39(4): p. 611625 . 